\title{
Fire Propagation Behavior of Electrical Cables
}

\author{
A. TEWARSON and M. M. KHAN \\ Factory Mutual Research Corporation \\ 1151 Boston-Providence Turnpike \\ Norwood, Massachusetts 02062, USA
}

ABSTRACT

Results are presented for the vertical fire propagation for 0.508 and $1.29 \mathrm{~m}$ long electrical cables in oxygen concentrations of 40 and $30 \%$, respectively. The bottom $40 \%$ of the $0.508 \mathrm{~m}$ long cable and $16 \%$ of the $1.29 \mathrm{~m}$ long cable are exposed to external heat flux with a peak value of $50 \mathrm{~kW} / \mathrm{m}^{2}$. In the experiments, measurements are made for heat release rates, generation rates of chemical compounds and optical density of smoke.

The vertical fire propagation rate for cables is found to be proportional to the ratio of the chemical heat release rate to thermal response, a relationship suggested by various fire propagation theories. Conditions where self-sustained fire propagation is not expected to occur have been identified: 1) critical or minimum heat flux for ignition $>20$ $\left.\mathrm{kW} / \mathrm{m}^{2} ; 2\right)$ vertical fire propagation rate $V<1.0 \times 10^{-3} \mathrm{~m} / \mathrm{s} ;$ and 3 ) chemical heat release rate/thermal response $<0.55 \mathrm{sec}^{-172}$. These conditions are satisfied in larger-scale firẽ propagation experiments for cables. The analysis suggests that it is possible to design a small-scale standard fire test for cables based on ignition, fire propagation and heat release rate.

\section{INTRODUCTION}

Electrical cables are used extensively for both residential and industrial applications. They consist of conductors made of either copper or aluminum and insulation (or jackets) of synthetic polymeric materials. Several types of polymeric materials are used in cable constructions, varying in chemical structure, thickness, and additives such as fire retardants, etc. Depending on the applications, cables are either packed loosely or tightly, in horizontal, vertical or other orientations. The polymeric materials in cable constructions burn when exposed to heat sources and have caused serious industrial fires in the past.

Currently, there are several test methods and procedures available for the flammability or fire resistance evaluation of cables. Some of the methods and procedures are included in national and international fire safety standards. It is, however, difficult to assess the large-scale fire behavior of cables using these standard tests. Thus, a study has been undertaken to understand the fire propagation behavior of cables and to explore the feasibility of developing a small-scale standard fire test 
for cables. The study is an extension of our previous studies on cables, where over 100 different types of cables were examined [1-2]. In this study, the fire propagation behavior of cables has been quantified in terms of ignition, vertical fire propagation, heat release, and generation of $\mathrm{CO}, \mathrm{CO}_{2}$, hydrocarbons, and smoke and optical density of smoke. This paper presents selected results of the study; other details are given in Reference [2].

\section{CONCEPTS}

\section{Ignition and Eire Propagation Rate}

Fire propagation results from the complex interaction of transport and chemical processes that occur in the vicinity of the boundary separating the burning and nonburning region [3]. For fire propagation, the heat balance at the surface has to be satisfied; the sum of the flame heat flux from the burning surface and other external heat fluxes has to be equal to or greater than the heat flux required for sustained flaming ignition of the nonburning surface. According to various theories, the self-sustained fire propagation rate is proportional to the ratio of the flame heat flux received by the unburned surface and the thermal response of the material $[3-4]$.

$$
v^{1 / 2} \quad \text { a } \quad \Phi^{1 / 2} / \Delta T\left(k \rho c_{p}\right)^{1 / 2} \text {, }
$$

where $\mathrm{V}$ is fire propagation rate in $\mathrm{m} / \mathrm{s} ; \Delta \mathrm{T}$ is the ignition temperature above ambient $(K), k$ is the thermal conductivity $(\mathrm{kW} / \mathrm{m}-\mathrm{K}) ; 0$ is the density $\left(\mathrm{kg} / \mathrm{m}^{3}\right) ; \mathrm{c}_{\mathrm{p}}$ is the specific heat $(\mathrm{kJ} / \mathrm{kg}-\mathrm{K})$; and $\Phi$ is the flame heat transfer paraneter $\left(\mathrm{kW}^{2} / \mathrm{m}^{3}\right)$, expressed as [4]:

$$
\phi=\left(\mathrm{q}_{\mathrm{f} l}^{\prime \prime}\right)^{2} \delta,
$$

where $\hat{q}_{\mathrm{f}}^{\prime \prime}$ is the flame heat flux $\left(\mathrm{kW} / \mathrm{m}^{2}\right)$ and $\delta$ is an effective heat transfer distance $(m)$.

From data correlations, it has been shown that $\mathcal{Q}_{f}^{\prime \prime}$ a $\left(\dot{Q}^{\prime \prime}{ }_{\mathrm{C}}\right)^{\mathrm{n}}$, where $\dot{Q}_{\text {" }}^{\prime \prime}$ is the chemical heat release rate $\left(\mathrm{kW} / \mathrm{m}^{2}\right)$ and $\mathrm{n}$ is Iess than
unity.

In Eq (1), $\Delta T\left(k p c_{p}\right)^{1 / 2}$ can be defined as the thermal response of the surface and is a function of time to ignition $[4,5]$ :

$$
\tau^{-1 / 2} \quad \alpha \quad q_{n}^{\prime \prime} / \Delta T\left(k \rho c_{p}\right)^{1 / 2},
$$

where $\tau$ is the time to ignition (sec) and $q_{n}^{\prime \prime}$ is the net heat flux absorbed by the material $\left(\mathrm{kW} / \mathrm{m}^{2}\right)$ :

$$
\dot{q}_{n}^{\prime \prime}=\dot{q}_{e x}^{\prime \prime}-\dot{q}_{c r}^{\prime \prime},
$$

where $\dot{q}_{c r}^{\prime}$ is the minimum or critical heat flux for ignition $\left(\mathrm{kW} / \mathrm{m}^{2}\right)$. Ignition data for numerous materials including cables have been reported $[1,2,4,5]$.

It has been shown that $\dot{q}_{f}^{\prime \prime}$ increases with the mole fraction of $\mathrm{O}_{2}$, $\mathrm{n}_{\mathrm{O}}$, in the environment [6]. Also, under fixed values of velocity and pressure, $V$ increases with $n_{0}$ [3]. Thus, fire propagation experiments can be performed, using forced flow conditions, where samples are exposed to external heat flux in an environment with variable $\mathrm{n}_{\mathrm{O}_{2}}$, inlet gas 
velocity and pressure. For the analysis of the results, Eqs. (1) to (4), in conjunction with the ignition data can be used. This concept has been used in our study, where cable construction, cable length and $n_{0}$ were the variables and $\dot{q}_{e x}^{\prime \prime}$ inlet gas velocity and pressure were maintained constant.

\section{Heat of Combustion and Heat Release Rate}

In flammability experiments, the generation rates of material vapors, chemical compounds such as $\mathrm{CO}, \mathrm{CO}_{2}$, hydrocarbons, smoke, etc., depletion rate of $\mathrm{O}_{2}$, convective heat release rate, and optical transmission are measured simultaneously [5]. The chemical heat release rate is then calculated from the generation rates of $\mathrm{CO}$ and $\mathrm{CO}_{2}$ and/or depletion rate of $\mathrm{O}_{2}$ [5]. If $\mathrm{A}$ is the surface area of the sample burning in $\mathrm{m}^{2}$, then:

$$
\dot{Q}_{\text {Chem }}=\dot{Q}_{\text {Chem }}^{\prime} A \text {, }
$$

where $Q_{\text {Chem }}$ is the chemical heat release rate in $\mathrm{kW}$. The cumulative value of $Q_{\text {Chem }}$ at time $t_{i}$, which is equal to energy $E_{i}$, can be expressed as:

$$
E_{i}=\int_{\tau}^{t_{i}} \dot{Q}_{\text {Chem }} d t,
$$

where $\tau$ is the time to ignition $(s) . \quad t_{j}$ is in seconds, and $E_{j}$ is in $k J$. The cumulative value of the generation rate of material vapors, $M$, can also be calculated. The chemical heat of combustion, $\Delta H_{\text {Chem, }}$ then can be defined as:

$\Delta H_{\text {Chem }}=E_{\mathrm{T}} / \mathrm{M}$,

where $E_{T}$ is the total energy generated $(\mathrm{kJ}) ; M$ is in $\mathrm{kg}$ and $\Delta \mathrm{H}_{\mathrm{Chem}}$ is in $\mathrm{kJ} / \mathrm{kg}$. Data for $\Delta \mathrm{H}_{\mathrm{Chem}}$ determined in this fashion as well as based on averages at the steady state conditions have been published $[5,7]$. This concept has been used in the study.

\section{Combustion Length}

In the flammability experiments $[5$,$] , the generation rate of material$ vapors, $\dot{G}_{V \text { ap }}^{\prime \prime}$ and $\dot{Q}_{C h e m}^{\prime \prime}$ are measured and $\mathrm{E}, \mathrm{M}$ and $\Delta \mathrm{H}_{\mathrm{Chem}}$ are calculated as functions or time. The accuracy of the calculated value of: 1) $M$ is established by the direct measurement of the residue after combustion; and 2) $\Delta \mathrm{H}_{\mathrm{Chem}}$ by direct measurements for heat of complete combustion, $\Delta \mathrm{H}_{\mathrm{Comp}}$, and elemental compositions and calculation of the combustion efficiency $[5,7]$.

The effective combustion length at any time $t_{i}$ can be calculated from the following relationship (details are given in Ref. 2):

$L_{t_{i}}=\left(E_{t_{i}} / E_{T}\right) L_{T}$,

where $L_{t}$. is the combustion length at $t_{i}(m) ; E_{t}$. is the energy generated at $t_{j}(k j) ; E_{T}$ is the total energy generated $\left(k J j\right.$ and $L_{T}$ is the total length of the sample $(\mathrm{m})$. The reliability of the calculations is verified by comparing the $\mathrm{E}_{\mathrm{T}} / \mathrm{L}_{\mathrm{T}}$ value calculated in the experiments with the $\mathrm{E}_{\mathrm{T}} / \mathrm{L}_{\mathrm{T}}$ value determined in the small-scale experiments under simulated largescale fire conditions. From the calculated data for $L_{t}$. as a function of time, the fire propagation rate, $v_{t_{1}}$, can be calculated.

$v_{t_{i}}=(d L / d t)_{t_{i}}$ 


\section{EXPERIMENTS}

The vertical fire propagation experiments were performed in our $500 \mathrm{~kW}-$ Elammability Apparatus, shown in Eigure 1. Fifty dif-ferent types of commercially available cables for industrial applications were used in the study with solid pine cylinders with variable diameters as reference.

The samples were placed at the location as marked in Figure 1. The sample was surrounded by a quartz tube connected to a Pyrex tube. Four coaxially placed tungsten-quartz radiant heaters were used for applying external heat flux to the bottom part of the cable sample. A small pilot flame was located near the sample for igniting the vapors. Air was introduced at the bottom of the apparatus at a known flow rate and oxygen concentration.

Air and products generated during the fire propagation were captured in the sampling duct, where various measurements were made.

\section{Ignition Experiments}

Time to piloted ignition was measured at different external heat flux values. Experiments were performed in the $10 \mathrm{~kW}-S c a l e$ Apparatus, using $0.10 \mathrm{~m}$ long vertical and horizontal cable samples with covered ends; no significant variations were found in the ignition data due to these conditions. The surfaces of the cables were covered with a thin layer of graphite powder.

From the measured data for time-to-ignition, the approximate range of external heat flux values, where ignition is not expected to occur, was determined and was used as a gujide for the actual measurement of $\dot{q}_{c r}^{\prime \prime}$. For the determination of $\Delta T\left(k \rho c_{p}\right) / 2$, regression analysis of the data was performed using Eq (3), assuming the proportionality constant to be unity.

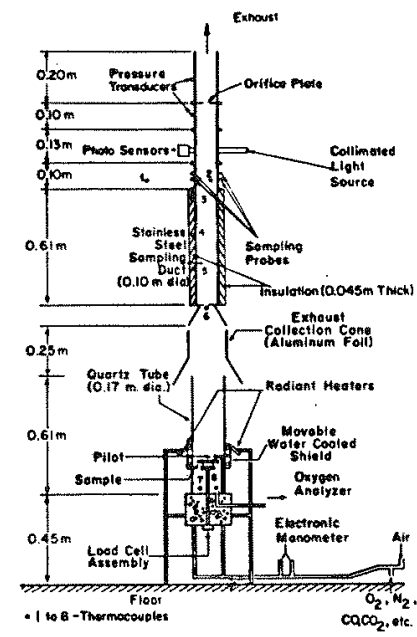

A

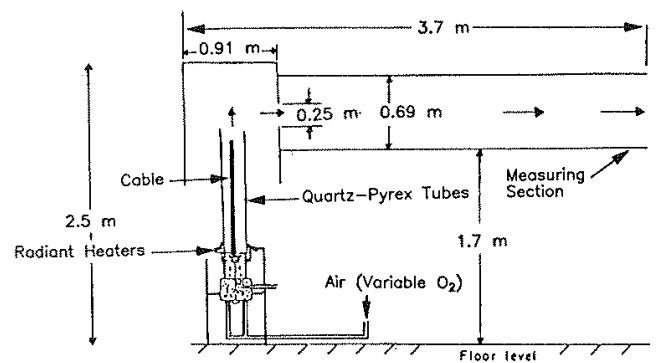

B

Figure 1. Flammability apparatus used: A) $10 \mathrm{~kW}-\mathrm{scale}$; and B) $500 \mathrm{~kW}-\mathrm{scale}$. 
$\Delta \mathrm{H}_{\text {Chem }}$ and $\mathrm{E}_{\mathrm{T}} / \mathrm{L}_{\mathrm{T}}$ values were determined from the flammability experiments in the $10 \mathrm{~kW}-S c a l e$ Apparatus. In the experiments, $0.10 \mathrm{~m}$ long vertical cable sample was exposed to $50 \mathrm{~kW} / \mathrm{m}^{2}$ in normal air and data were obtained for $\dot{Q}_{C h e m}^{\prime \prime}, \dot{G}_{\text {Lap, }}^{\prime \prime}, E_{T}, L_{T}$ and the residue. From the data, values for $\Delta \mathrm{H}_{\mathrm{Chem}}$ and $\mathrm{E}_{\mathrm{T}} \mathrm{L}_{\mathrm{T}}$ were calculated. The accuracy of $\Delta \mathrm{H}_{\mathrm{Ch}}$ values were checked using data for similar polymeric materials $[5,7]$, whenever it was possible.

\section{Eire Propagation Experiments}

The vertical fire propagation experiments were performed in the $500 \mathrm{kw}$-Scale Apparatus, using 0.508 or a $1.29 \mathrm{~m}$ vertical cable samples surrounded by a $0.9 \mathrm{~m}$ long quartz tube extended to $1.8 \mathrm{~m}$ by using a Pyrex tube with a metal attachment.

The heat flux distribution from the four coaxially placed radiant heaters was calibrated within the cable sample zone; the heat flux zone was present from 0 to $0.20 \mathrm{~m}$ of the vertical length of the sample zone. Thus in the experiments, the bottom $40 \%$ of the $0.508 \mathrm{~m} \mathrm{long}$ and $16 \%$ of the $1.29 \mathrm{~m}$ long cable samples were in the external heat flux zone. Fire propagation experiments were performed with $q_{e x}^{\prime \prime}=50 \mathrm{~kW} / \mathrm{m}^{2}$ with $n_{\mathrm{O}_{2}}$ in the range of 0.209 to 0.450 and an inlet gas velocity of $0.11 \mathrm{~m} / \mathrm{s}$ (asyptotic limit where gas velocity has negligible effect on fire propagation in our apparatus). The vapors generated from the cable samples were ignited by a small pilot flame. In the experiments, measurements were made, as functions of time, for the generation rates of $\mathrm{CO}, \mathrm{CO}_{2}$, smoke and total gaseous hydrocarbons, optical density of smoke, depletion rate of $\mathrm{O}_{2}$, gas temperature, and total mass and volumetric flow rates. Visual observations were made for time to ignition and fire propagation.

\section{EXPERIMENTAL RESULTS}

In the experiments, cables were used varying in: 1) insulation and jacketing materials - thickness, chemical structure and fire retardunt and other additives; 2) diameter; 3) type of metal used as conductor and number of conductors; and 4) commercial applications-electrical power, telephone, instrumentation, control and signaling. Some selected cables are listed in Table 1 and are identified in terms of numbers with corresponding polymeric materials used as insulation and facket and the diameter of the cable.

\section{Ignition}

The ignition experiments were performed in the $10 \mathrm{~kW}$-Scale Apparatus where $\tau$ was measured at various quex values; $\dot{q}_{\text {chr }}^{\prime \prime}$ was also measured, which is defined as a flux at or below which there is no ignition of vapors in the gas phase. The thermal response, $\Delta \mathrm{T}\left(\mathrm{kpc}_{\mathrm{p}}\right)^{1 / 2}$, was derived from the data as discussed previously. The data for Selected cables are listed in Table 1. Cables with $\dot{\mathrm{q}}_{\mathrm{c}}^{\prime \prime} \geq 20 \mathrm{~kW} / \mathrm{m}^{2}$, show higher resistance to ignition and fire propagation. The 'qu values reported in Table 1 are in agreement with the values for similar polymeric materials, except for cases where there were additives present in the polymers and surface absorptivities were different $[1,2,5]$.

According to Eq. (1), the higher the value of the thermal response, the slower the fire propagation rate. The thermal response depends on the 
chemical structure of the polymers and additives, their thicknesses, cable diameter, etc. Figure 2 shows selected examples of the data, where an increase in the slope represents increase in the thermal response of the cable. The data in Table 1 show that, in general, the thermal response is higher for cables with larger diameters (higher mass of the conductor); thermal response also shows dependency on the chemical structures and/or additives.

\section{Chemical Heat of Combustion and Energy per Unit Cable Length}

$\Delta \mathrm{H}_{\mathrm{Chem}}$ and $\mathrm{E}_{\mathrm{T}} / \mathrm{L}_{\mathrm{T}}$ were determined using $0.10 \mathrm{~m}$ long vertical cable in the $10 \mathrm{~kW}$-Scale Apparatus. The data for $\Delta \mathrm{H}_{\mathrm{Ch}}$ for selected cables are listed in Table 1. Since the polymeric materlals used as insulation and jacket contain fire retardant and other additives, the values of $\Delta H_{C h e m}$ reported in Table 1 may not agree with the $\Delta H_{C h e m}$ values for pure polymers.

\section{Eire Propagation}

In the fire propagation experiments, $V$ was calculated from Eqs. (8) and $(9)$. The values of $E_{\mathrm{T}} / \mathrm{L}_{\mathrm{T}}$, determined in the experiments, were

Table 1. Data for Ignition, Heat Release and Fire Propagation for Electrical Cables

\begin{tabular}{|c|c|c|c|c|c|c|c|c|c|c|}
\hline \multirow{3}{*}{$\begin{array}{l}\text { Cable } \\
\text { No. }\end{array}$} & \multirow{2}{*}{\multicolumn{2}{|c|}{ Polymerlo Materlats }} & \multirow{3}{*}{$\begin{array}{l}\text { Olameter } \\
\text { (m) }\end{array}$} & \multirow{3}{*}{$\dot{q}_{\mathrm{cr}}^{\mathrm{a}}{ }_{\left(\mathrm{kW} / \mathrm{m}^{2}\right)}^{\mathrm{a}}$} & \multirow{3}{*}{$\begin{array}{c}\Delta T\left(k p c p_{p}\right)^{1 / 2, a} \\
\left(k W / m^{2}\right) g^{1 / 2}\end{array}$} & \multirow{3}{*}{$\begin{array}{c}\Delta H_{C h e 0^{-3}}^{a} \\
(k J / k g)\end{array}$} & \multicolumn{2}{|c|}{$L=0.508 \mathrm{~m}^{\mathrm{D}, c}$} & \multicolumn{2}{|c|}{$L-1,29 \mathrm{~m}^{6, d}$} \\
\hline & & & & & & & $6 \times 10^{3}$ & $Q_{\text {Chem }}^{M}$ & $v \times 10^{3}$ & Q Cunem \\
\hline & Insulat ion & Jacket & & & & & $(m / s)$ & $\left(\mathrm{kW} / \mathrm{m}^{2}\right)$ & $(\mathrm{m} / \mathrm{s})$ & $\left(\mathrm{kW} / \mathrm{m}^{2}\right)$ \\
\hline 1 & PVC & PVC & 0.0036 & 15 & 131 & 18.9 & 13.0 & 735 & - & - \\
\hline 2 & PVC & PVC & 0.0044 & 15 & 156 & 18.1 & 12.0 & 802 & - & - \\
\hline 3 & PVC & PVC & 0.0092 & 13 & 267 & 12.6 & 4.8 & 441 & 4.5 & 352 \\
\hline 4 & PVC & PVC & 0.013 & 25 & 341 & 16.5 & 3.3 & 477 & - & 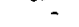 \\
\hline 5 & $P E$ & PVC & 0.0037 & 20 & 183 & 20.9 & 14.0 & 1211 & - & - \\
\hline 6 & EP & PVC & 0.011 & 15 & 244 & 13.4 & 2.3 & 268 & 1.4 & 190 \\
\hline 7 & PVC & EP & 0.034 & 15 & 263 & 12.6 & 0.58 & 89 & - & - \\
\hline 8 & S1 & PVC & 0.016 & 19 & 212 & 15.1 & 1.4 & 131 & 1.1 & 98 \\
\hline 9 & PE & $P E$ & 0.0094 & 15 & 270 & 12.0 & 5.4 & 653 & 6.0 & 567 \\
\hline 10 & $P E$ & $P E-C Q$ & 0.0094 & 25 & 219 & 11.2 & 2.3 & 263 & - & - \\
\hline 11 & $\mathrm{EP}$ & $E P$ & 0.010 & 20 & 467 & 17.1 & 2.1 & 327 & 1.3 & 296 \\
\hline 12 & EP & EP & 0.016 & 23 & 499 & 16.6 & 0.75 & 205 & 0.68 & 176 \\
\hline 13 & $E P$ & $\varepsilon P$ & 0.025 & 23 & 567 & 19.7 & 0.65 & 301 & 0.53 & 256 \\
\hline 14 & XPE & XPE & 0.0095 & 20 & 273 & 12.4 & 5.0 & 535 & 3.7 & 401 \\
\hline 15 & XPE & XPE & 0.0099 & 25 & 382 & 18.2 & 2.4 & 405 & 2.9 & 500 \\
\hline 16 & XPE & XPE & 0.011 & 22 & 386 & 19.4 & 3.1 & 502 & - & - \\
\hline 17 & XPE & XPE & 0.012 & 24 & 276 & 14.0 & 1.9 & 232 & 1.4 & 229 \\
\hline 18 & $x p \varepsilon$ & EVA & 0.012 & 25 & 503 & 17.2 & 1.6 & 543 & - & 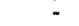 \\
\hline 19 & XPE & EVA & 0.017 & 25 & 460 & 21.6 & 1.0 & 216 & - & - \\
\hline 20 & XPE & EVA & 0.022 & 20 & 442 & 22.0 & 0.99 & 194 & 0.74 & 124 \\
\hline 21 & $\mathrm{XPE}$ & $\mathrm{PCP}$ & 0.015 & 20 & 291 & 12.9 & 1.0 & 163 & - & 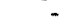 \\
\hline 22 & XPO & XPO & 0.016 & 20 & 463 & 14.0 & 1.5 & 369 & 1.9 & 918 \\
\hline 23 & $\varepsilon P$ & $P E-C Q-S$ & 0.0035 & 25 & 289 & 30.9 & 7.8 & 965 & - & - \\
\hline 24 & $\mathrm{EP}$ & $\mathrm{PE}-\mathrm{Cl}-\mathrm{S}$ & 0.0043 & 20 & 343 & 15.9 & 7.3 & 943 & - & - \\
\hline 25 & EP & $P E-C Q-S$ & 0.011 & 18 & 283 & 18.9 & 1.7 & 275 & - & - \\
\hline 26 & $E P$ & $P E-C \&-S$ & 0.016 & 20 & 415 & 19.3 & 1.1 & 320 & 1.2 & 328 \\
\hline 27 & EP & $P E-C 2-S$ & 0.019 & 20 & 416 & 20.1 & 1.4 & 354 & 1.1 & 266 \\
\hline 28 & $E P-F R$ & None & 0.015 & 25 & 370 & 14.8 & 1.9 & 359 & - & - \\
\hline 29 & $E P-F R$ & None & 0.018 & 20 & 443 & 15.1 & 2.5 & 475 & - & - \\
\hline 30 & $F P-F R$ & None & 0.028 & 19 & 295 & 14.8 & $\because$ & & 0.54 & 91 \\
\hline 31 & $P E-C Q$ & None & 0.015 & 12 & 217 & 11.6 & 2.3 & 224 & 1.90 & 145 \\
\hline 32 & ETFE & $E k$ & 0.010 & 22 & 454 & 11.2 & 1.9 & 380 & - & - \\
\hline 33 & PVF & None & 0.0050 & 30 & 264 & 6.0 & $t$ & 48 & - & $=$ \\
\hline 34 & FEP & FEP & 0.0079 & 36 & 652 & 6.2 & - & 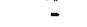 & f & 91 \\
\hline 35 & EEP & FEP & 0.0092 & 30 & 638 & 9.8 & e & 115 & - & - \\
\hline $36^{\circ}$ & Solld & Plne & 0.013 & 10 & 289 & 12.4 & $=$ & - & 5.0 & 552 \\
\hline $37^{e}$ & solid & pine & 0.019 & 10 & 337 & 12.4 & - & - & 2.7 & 404 \\
\hline $38^{\circ}$ & Solto & Plne & 0.029 & 10 & 401 & 12.4 & - & - & 2.0 & 361 \\
\hline
\end{tabular}

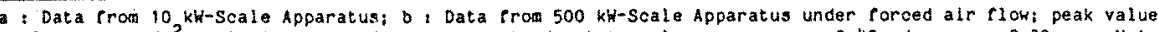

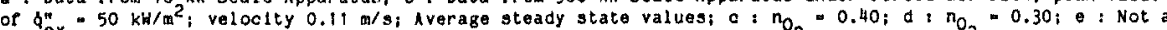
cable, used as a reference; $f$ : Melting polymer, difflcult to measure; -7 Not measured; $2 R$ : Chlorlnated; Cl-s ; Chloro-Sulfonated; EA : Ethylene-acryllo copolymer; EP : Ethylene-propylene copolymer; EVA :

Ethylene-ylnyl acetat copol yer: ETFE. Ethyleno-tetra fluoroethylene copolymer; Fa : Fire retarded; FEP. Fluorinated athylene propylene; PE: Polyethylene; PCP: Polychloroprene; PVC: Poly (yInylenloride); PVF : Poly(viaylldene fluoride); Si: Sllicone; Xe ; Cross-1inked polyethylene; XPo: Crcss-1inked polyolerin. 
compared with the values of $E_{T} / L_{T}$ determined in the $10 \mathrm{~kW}$-Scale Apparatus. In some cases there were disagreements, especially for those cases where fire did not propagate to the end of the cable. For such cases, the $\mathrm{E}_{\mathrm{T}} / \mathrm{L}_{\mathrm{T}}$ values from the $10 \mathrm{~kW}$-Scale Apparatus were used.

In the experiments, $1.29 \mathrm{~m}$ long, solid pine cylinders with diameters of $0.013,0.019$ and $0.029 \mathrm{~m}$ were also used. The values of $V$ for the pine cylinders as functions of $L$ are shown in Eigure 3 , for $n_{0}=0.30$. The thermal response values for the cylinders are given in Table 1. As can be noted, $V$ decreases with increase in $d$, following the dependency on thermal response as expected from Eq. (1).

Fire propagation experiments were performed at various values of $\mathrm{n}_{2}$ in order to vary $V$. Figure 4 shows an example for the cross-1inked polyethylene cable. As can be noted, $V$ increases with $n_{O_{2}}$; fire does not propagate to the end of the cable when $n_{O_{2}} \leq 0.25$; whereas for $n_{O_{2}}=0.30$, fire propagation is complete. For $L$ values in the range of about 20.01 to $0.25 \mathrm{~m}$, and in the range of 0.50 to $1.1 \mathrm{~m}$, steady-state conditions are present. These two zones were found for all the cables examined in this study. It was thus possible to calculate the average values of $V$ in these two zones. In addition, from the $L$ values, for the steady-state conditions, it was possible to calculate the burning surface area, $A$, of the cables and calculate $\dot{Q}_{C h e m}^{\prime \prime}$ in $\mathrm{kW} / \mathrm{m}^{2}$. Some selected data for the average steady-state values of ${ }_{\text {and }} \dot{Q}^{\prime \prime}$ are $l$ isted in Table 1 . It should be pointed out that for $\mathrm{n}_{\mathrm{O}} \geq 0.38$, $\mathrm{q}_{\mathrm{f}}$, reaches an asymptotic value, comparable to values expected 2 in large-scate fires $[6,8]$; the data 1 isted in Table 1 thus are expected to represent large-scale fire propagation behavior of cables.

According to fire propagation theories [3-4], Eq. (1) can be expressed as:

$$
v^{1 / 2} \quad \alpha \quad \dot{Q}_{C h e m}^{\prime \prime} / \mathrm{T}\left(k \rho c_{p}\right)^{1 / 2} .
$$

Data for all the terms in Eq. (10) are listed in Table 1 and thus the validity of the relationship can be tested for fire propagation in cables involving complex combination of polymers and metals. This is shown in Figure 5, where an excellent agreement between $V$ and the ratio of the

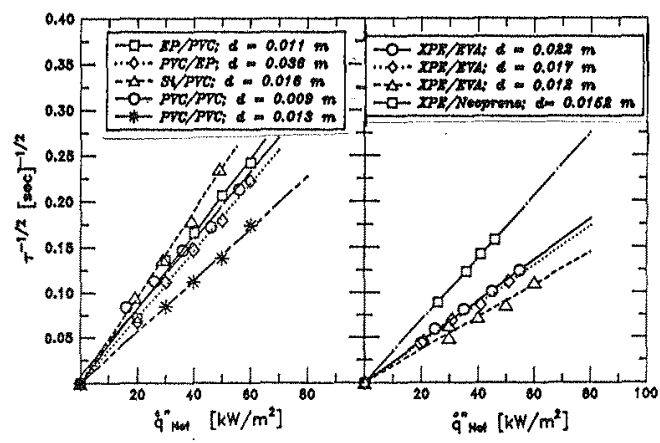

Figure 2. Relationship between time to ignition and net heat flux absorbed by the cable surface.

d: diameter.

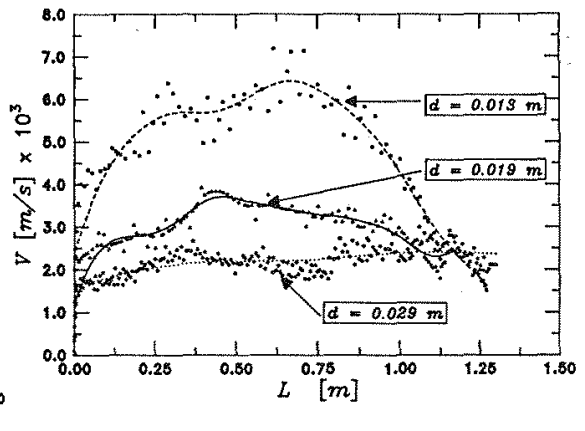

Figure 3. Vertical fire propagation rate versus length for solid pine cylinders.

d: diameter. 
chemical heat release rate to thermal response can be noted, except for polymers which melt faster than the rate of upward fire propagation. In Figure 5 , values of $V$ and $\dot{Q}_{C h e m}^{\prime \prime} / T\left(k \rho c_{p}\right)^{172}$ are identified at or below which self-sustained fire propagation was not observed in the experiments. These conditions have been successfully validated in larger-scale fires [2].

\section{DISCUSSION}

The analysis presented in this paper show that the relationships suggested by various fire propagation theories [3-4] are applicable to cables. Data in Table 1 and Figure 5 and visual observations suggest the following conditions for non-self-sustained fire propagation. in our apparatys: 1) $\left.\mathrm{g}^{\prime \prime}>20 \mathrm{~kW} / \mathrm{m}^{2} ; 2\right) \mathrm{V} \leqslant 1.0 \times 10^{-3} \mathrm{~m} / \mathrm{s} ;$ and 3) $\dot{Q}_{\mathrm{Chem}}^{\prime \prime} / \Delta \mathrm{T}$ $\left(\mathrm{k} \rho \mathrm{c}_{\mathrm{p}}\right)^{1 / 2} \lesssim 0.55^{\mathrm{r}} \mathrm{secc}^{-1 / 2}$.

The chemical heat release rate in Eq. (10) can be expressed as:

$$
\dot{Q}_{\text {Chem }}^{\prime \prime}=\left(\Delta \mathrm{H}_{\text {Chem }} / L_{\mathrm{g}}\right) \dot{q}_{\mathrm{n}}^{*} \quad \text {, }
$$

where $L_{\mathrm{g}}$ is the heat of gasification $(\mathrm{kJ} / \mathrm{kg})$. From Eqs. (10) and (11), $\mathrm{V}^{1 / 2} \quad \alpha \quad\left(\Delta \mathrm{H}_{\mathrm{Chem}} / \mathrm{L}_{\mathrm{g}}\right)\left[\dot{\mathrm{q}}_{\mathrm{n}}^{\prime \prime / \Delta \mathrm{T}}\left({\mathrm{k} \rho \mathrm{c}_{\mathrm{p}}}\right)^{1 / 2}\right]$

and from Eqs. (3) and (12),

$\mathrm{V}^{1 / 2} \quad \alpha \quad\left(\Delta \mathrm{H}_{\mathrm{Chem}} / \mathrm{L}_{\mathrm{g}}\right) \mathrm{r}^{-1 / 2}$

Eqs. (12) and (13) suggest that polymers with low values of heat of combustion, high values of heat of gasification and thermal inertia are expected to have low values of $V$. Data for $\Delta \mathrm{H}_{\mathrm{Chem}}$ and $\Delta \mathrm{T}\left(\mathrm{kp \textrm {c } _ { \mathrm { p } }}\right) \mathrm{T}$ are included in Table 1; values of $\mathrm{L}_{\mathrm{g}}$, however, were not measured. $\Delta \mathrm{H}_{\mathrm{Chem}}$ values depend on the chemical stpucture of the polymers; values are high for polymers based on aliphatic hydrocarbons; are intermediate for polymers based on aromatic hydrocarbons and are low for highly halogenated polymers. Introduction of 0 atom in the structure of the polymer results in a decrease in $\Delta \mathrm{H}_{\text {Chem }}$ values [7]. $\mathrm{L}_{\mathrm{g}}$ values depend on the chemical bonds in the polymer and increase with ${ }^{\mathrm{g}}$ increase in the charring tendencies
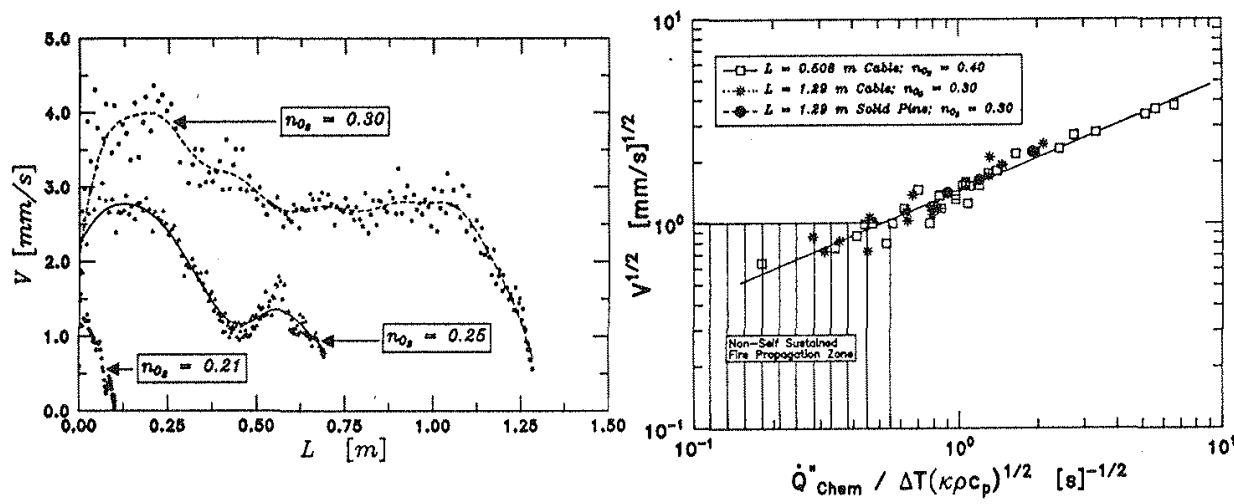

Figure 4. Vertical fire propagation rate versus cable length for cross-linked polyethylene cable.
Figure 5. Vertical fire propagation rate for electrical cables as a function of the ratio of chemical heat release rate and thermal response. 
of the polymers. It is thus possible to explain the differences in the $V$ values for cables, based on $\Delta \mathrm{H}_{\mathrm{Chem}}, L_{g}$ and $\Delta \mathrm{T}\left({\mathrm{K} \rho \mathrm{C}_{\mathrm{p}}}\right)^{1 / 2}$. Radiation differences also need to be accounted for.

It is interesting to compare values for $\dot{Q}_{C h e m}^{\prime \prime}, \Delta \mathrm{T}\left(\mathrm{k} \rho \mathrm{c}_{\mathrm{p}}\right)^{1 / 2}, \dot{\mathrm{q}}_{\mathrm{c} r}^{\prime \prime}$ and self-sustained fire propagation behavior for polymers in the form of resins and as insulation and jacketing materials. Table 2 lists data for selected polymers, where it can be noted that polymers with char-forming tendencies and lower $\Delta \mathrm{H}_{\mathrm{Chem}}$ values satisfy the conditions for non-selfsustained fire propagation.

Table 2. Critical Heat Flux, Thermal Response and Chemical Heat Release Rate for Selected Materials and Cables ${ }^{a}$

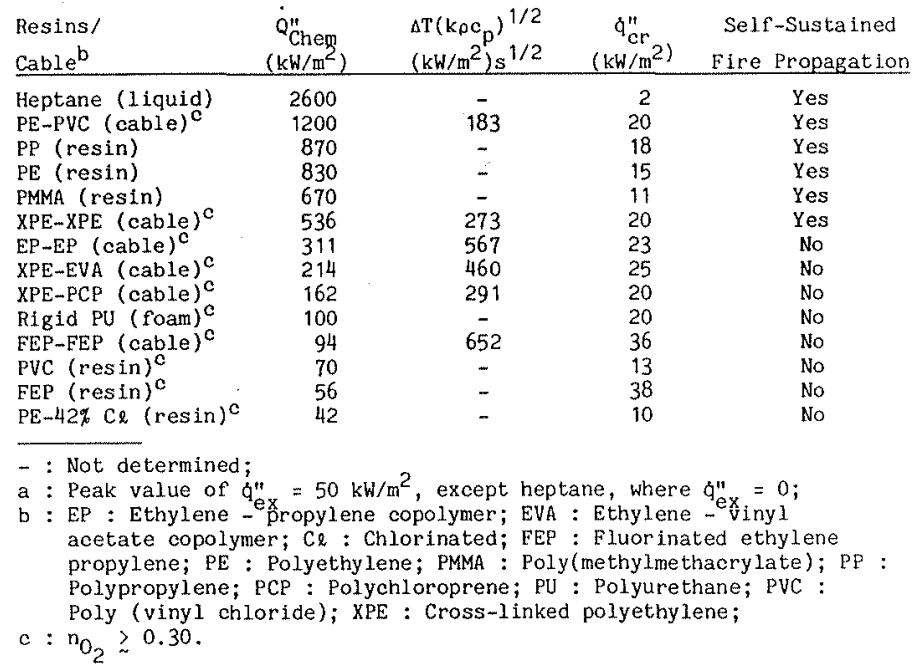

\section{SUMMARY}

1. Relationships suggested by various fire propagation theories [3-4] are applicable to cables;

2. It is possible to identify conditions under which self-sustained fire propagation is pot expected. The conditions are $\mathrm{g}^{\prime \prime} \geq 20 \mathrm{~kW} / \mathrm{m}^{2}$, Q" $/ \Delta \mathrm{T}(\mathrm{koc}))^{192}<0.55 \mathrm{~s}^{-1 / 2}$ and $v<1 \times 10^{-3} \mathrm{cr} / \mathrm{s}$. Larger-scale cable fire propagation experiments support thẽse conditions [2];

3. The differences in the fire propagation behavior of cables are suggested to be due to differences in the chemical heat of combustion, heat of gasification, thermal inertia and radiative properties.

4. It is possible to propose a standard small-scale fire.test for cables, where simultaneous measurement can be made for $V, Q_{C h e m}^{\prime \prime} q_{c r}^{\prime \prime}$, $\left.\Delta \mathrm{T}(\mathrm{k \rho c})^{1}\right)^{2}$, and smokiness (radiation) for at least $0.5 \mathrm{~m}$ Iong 'cable with $n_{0}>8.40$ and $q^{\prime \prime}=50 \mathrm{~kW} / \mathrm{m}^{2}$ for limited exposure of the cable. In the test, the cables should be used in their end-use configuration. 


\section{REEERENCES}

1. Tewarson, A., Khan, M.M., and Steciak, J., "Combustibility of Electrical Wire and Cable for Rail Rapid Transit Systems, Volume 1. Flammability, "U,S. Dept. of Transportation, Technical Report DOTTSC-UMTA-83-4, 1, April 1982, Nat'1. Technical Information Service, Springfield, VA 22161.

2. Tewarson, A., and Khan, M.M., "Electrical Cables - Evaluation of Fire Propagation Behavior and Development of a Fire Test Method," Technical Report OM2E1.RC Factory Mutual Research Corporation, Norwood, MA, April, 1988.

3. Fernandez-Pello, A.C., and Hirano, T., "Controlling Mechanisms of Flame Spread," Combustion Science and Technology, 32, 1 (1983).

4. Quintiere, J., and Harkleroad, M., "New Concepts for Measuring Flame Spread Properties," ASTM/SFPE Symposium, National Bureau of Standards, Center for Fire Research, Gaithersburg, MD (1984).

5. Tewarson, A., "Experimental Evaluation of Flammability Parameters of Polymeric Materials," Chapter 3, p. 97 in Flame Retardant Polymeric Materials, Volume 3, M. Lewin; S.M. Atlas; and E.M. Pearce (Editors), Plenum Press, New York, NY (1982).

6. Tewarson, A., Lee, J.L., and Pion, R.F., "The Influence of Oxygen Concentration on Fuel Parameters for Fire Modeling," 18th Symposium (International) on Combustion, The Combustion Inst., Pittsburgh, PA, p. $563(1981)$.

7. Tewarson, A., "Generation of Heat and Chemical Compounds in Eires," SFPE Quantitative Methods Handbook, Section I, Chapter 13, National Fire Protection Association, Quincy, MA, (in press).

8. Tewarson, A., and Newman, J.S., "Scale Effects on Fire Properties of Materials," Proceedings of the First International Symposium of Fire Safety Science, Hemisphere Publ. Corporation, New York, NY p. 451 $(1986)$. 